\title{
Early toxicity of hypofractionated radiotherapy for prostate cancer
}

\author{
Pavel Krupa a,b, Hana Tichac, Tomas Kazdaa , Radana Dymackovaa , Jana Zitterbartova a, Anna Odlozilikovac, Libor Komineka, \\ Lukas Bobek ${ }^{\mathrm{a}}$, Ales Kudlacek ${ }^{\mathrm{a}}$, Pavel Slampa ${ }^{\mathrm{a}, \mathrm{b}}$
}

Background. Hypofractionated accelerated radiotherapy (HART) is now a feasible option for prostate cancer treatment apropos toxicity, biochemical control and shortening of treatment. The aim of this study was to investigate hypofractionated schedules in the treatment of patients with localized prostate cancer.

Patients and Methods. Between 2011-2014, 158 patients were treated using the RapidArc technique with IGRT. The target volume for low risk patients was the prostate alone with a prescribed dose of 20x3.0 Gy (EQD2=77 Gy). Targets volumes for intermediate and high risk patients were prostate and two thirds of the seminal vesicles with a prescribed dose 21-22x3.0/2.1 Gy (EQD2=81/45.4-84.9/47.5). Based on radiobiological modelling of early toxicity, we used four fractions per week in the low risk group and four fractions in odd weeks and three fractions in even weeks in intermediate and high risk groups. The RTOG/EORTC toxicity scale was used.

Results. Early genitourinary (GU) toxicity was observed for grades 0, 1, 2, 3 and 4 in $73(46 \%), 60$ (38\%), 22 (14\%), 0 and $3(2 \%)$, respectively; early gastrointestinal (GI) toxicity was recorded for grades $0,1,2$ and 3 in $119(75 \%), 37(23 \%)$, and 2 (1\%) patients, respectively.

Conclusion. A combination of moderate hypofractionation, number of fractions per week adapted to target volume and precise dose delivery technique with image guidance appears safe with low early toxicity. Longer follow up is needed to assess late toxicity and tumor control probability.

Key words: hypofractionationation, VMAT, volumetric arc therapy, RapidArc, Tumor control probability, Normal tissue complication probability, alternated time schedule

Received: September 13, 2015; Accepted with revision: February 10, 2016; Available online: March 4, 2016 http://dx.doi.org/10.5507/bp.2016.008

${ }^{a}$ Clinic of Radiation Oncology, Masaryk Memorial Cancer Institute, Brno, Czech Republic

${ }^{b}$ Regional Centre for Applied Molecular Oncology, Masaryk Memorial Cancer Institute, Brno, Czech Republic 'Department of Medical Physics, Masaryk Memorial Cancer Institute, Brno, Czech Republic

Corresponding author: Pavel Krupa, e-mail: krupa@mou.cz

\section{INTRODUCTION}

Prostate cancer is now one of the most common malignant diseases in men in the USA. Expansion of PSA screening has led to a remarkable rise in low-risk prostate cancer detection ${ }^{1}$. Conventional fractionated radiotherapy, provided for eight weeks, is one of the longest schedules in radiation oncology practice. Shortening the overall treatment period is advantageous from many points of view, including patient compliance and economic considerations. Increasing numbers of clinical trials discussed below show the non-inferiority of hypofractionated accelerated radiotherapy (HART) in comparison to conventionally fractionated curative radiotherapy of prostate cancer. From the radiobiology point of view, the most important is the $\alpha / \beta$ ratio, which appears to be much lower for prostate cancer than for other tumors. Moreover, it appears to be even lower than the value of late reacting tissues $^{2}$. The most frequtly published value is $\alpha / \beta=1.5 \mathrm{~Gy}$ $\left(\right.$ ref. $\left.^{3}\right)$. The lower the $\alpha / \beta$ ratio is, the higher the response to increased dose per fraction of ionizing radiation. In other words, the same equivalent dose to tumor and lower equivalent dose to surrounding tissues, including these responsible for late toxicity, may be achieved by HART. This assumption is supported by a number of current clinical studies $^{47}$. However, with increasing dose per fraction, the probability of early toxicity rises. Extracranial Stereotactic radiotherapy uses high doses per fraction, usually 7-10 Gy in 4-5 fractions. Precise dose delivery and image guidance systems, mostly using robotic linear accelerator and automatic fiducials tracking, are used. Mild hypofractionation uses lower doses per fraction, usually 2.5-4 Gy. Taking into account the phenomenon of repopulation, we assume that partial reduction of early effects may be achieved by inserting free days into the fractionation schedule ${ }^{2}$. The aim of this study was to confirm that the hypofractionated regimens used were feasible without undue early toxicity and with perspective to show acceptable late toxicities and disease control.

\section{PATIENTS AND METHODS}

\section{Patients}

Between January 2011 and March 2014, 158 patients with localized, histologically confirmed prostate adenocarcinoma were treated at the Masaryk Memorial Cancer Institute in Brno, Czech Republic with volumetric modulated arc therapy (RapidArc) $\left(\right.$ ref. $\left.^{8}\right)$. Patients were stratified into two risk groups according to NCCN clinical 
guidelines in oncology, Prostate cancer, version 1.2011 (ref. $^{9}$ ) as low risk (PSA $<10 \mathrm{ng} / \mathrm{mL}$, GS $\leq 6$, T1-T2a) as one group and intermediate risk (PSA $10-20 \mathrm{ng} / \mathrm{mL}$ or $\mathrm{GS}=7$ or T2b-T2c) and high risk (PSA $>20 \mathrm{ng} / \mathrm{mL}$, or $\mathrm{GS}>7$, or T3a) together as the second group. This classification was based on the work of D'Amico et al. ${ }^{10}$. Basic patient characteristics are summarized in Table 1.

\section{Schedule preparation}

In preparing the HART schedule, dose volume histograms of 80 patients were analyzed using the methods of radiobiological modeling of normal tissue complication probability (NTCP) and tumor control probability (TCP) (ref. $\left.{ }^{11}\right)$. We searched for a universal scheme that metthe criteria for isoeffectiveness (TCP) and isotoxicity (NTCP) evaluated for early and late toxicity for rectum and bladder. For late toxicity, Quantec ${ }^{12,13}$ data were used. For early toxicity we used data published by Strigari et al. Radiobiological modeling was performed with the Biogray software $^{14}$. For each DVH a set of TCP and NTCP values was obtained. Then we searched for an appropriate schedule with 3.0 Gy per dose. The models used took into account the repopulation factor. In this way, early toxicity depending on number of free days per week could be modeled. Two separate schedules for different irradiated volumes (for prostate alone and for prostate and two thirds of the seminal vesicles) were created. For prostate alone, the final scheme was 20x3.0 Gy, 4 days per week ( $77 \mathrm{~Gy}$ with conventional fractionation). For irradiating the prostate and $2 / 3$ of the seminal vesicles as PTV1 and prostate alone as PTV2, the prescribed doses were 21-22 x 3.0 Gy for PTV2 a and 21-22 x 2.1 Gy for PTV1, alternately 3 and 4 days per week, using simultaneous integrated boost technique. The doses corresponded to 81-84.9 Gy and 45.4-47.5 Gy with conventional fractionation.

\section{Radiotherapy planning and patient preparation}

Standard planning CT study of pelvis with $3 \mathrm{~mm}$ slice thickness was performed with iodine contrast agent administrated half an hour before scanning. After administration, patients were instructed to urinate and drink 0.5 $\mathrm{L}$ of water, in order to have a conformably full bladder at the time of CT scanning. Organs at risk (bladder, rectum from anal sphincter to sigmoid junction and both femoral heads) were contoured by a radiation oncologist. In low risk patients, clinical target volume included prostate alone, while in intermediate and high risk patients, two clinical target volumes were defined - prostate with two thirds of the seminal vesicles and prostate alone. Image of contrast agent in bladder was used to precisely differentiate the border between bladder and prostate prominence, if present. In order to calculate the correct dose margin,

Table 1. Patient's characteristics.

\begin{tabular}{|c|c|c|c|}
\hline & Low risk & $\begin{array}{l}\text { Intermediate } \\
\text { and high risk }\end{array}$ & All \\
\hline Number of patients & 48 & 110 & 158 \\
\hline Median of age & 74 & 75 & 74 \\
\hline Median of follow-up (months) & 28 & 20 & 22 \\
\hline Median of PSA $(\mathrm{ng} / \mathrm{mL})$ & 6.4 & 9.1 & 7.6 \\
\hline \multicolumn{4}{|c|}{ Gleason score (GS) } \\
\hline $\mathrm{GS}=3$ & $1(2 \%)$ & $1(1 \%)$ & $2(1 \%)$ \\
\hline $\mathrm{GS}=4$ & $1(2 \%)$ & $0(0 \%)$ & $1(1 \%)$ \\
\hline $\mathrm{GS}=5$ & $6(13 \%)$ & $1(1 \%)$ & $7(4 \%)$ \\
\hline $\mathrm{GS}=6$ & $40(83 \%)$ & $29(26 \%)$ & $69(44 \%)$ \\
\hline $\mathrm{GS}=7$ & $0(0 \%)$ & $72(65 \%)$ & $72(46 \%)$ \\
\hline $\mathrm{GS}=8$ & $0(0 \%)$ & $5(5 \%)$ & $5(3 \%)$ \\
\hline $\mathrm{GS}=9$ & $0(0 \%)$ & $2(2 \%)$ & $2(1 \%)$ \\
\hline \multicolumn{4}{|c|}{ T Stage } \\
\hline $\mathrm{T} 1$ & $39(81 \%)$ & $61(56 \%)$ & $100(63 \%)$ \\
\hline $\mathrm{T} 2$ & $9(19 \%)$ & $45(41 \%)$ & $54(34 \%)$ \\
\hline $\mathrm{T} 3$ & $0(0 \%)$ & $4(3 \%)$ & $4(3 \%)$ \\
\hline N1 Stage & $0(0 \%)$ & $0(0 \%)$ & $0(0 \%)$ \\
\hline Hormonal therapy & $20(42 \%)$ & $65(59 \%)$ & $85(54 \%)$ \\
\hline Intervention on prostate & $2(4 \%)$ & $2(2 \%)$ & $4(3 \%)$ \\
\hline \multicolumn{4}{|c|}{ Risk Group (NCCN) } \\
\hline Low risk & $48(100 \%)$ & $0(0 \%)$ & $48(30 \%)$ \\
\hline Intermediate risk & $0(0 \%)$ & $94(85 \%)$ & $94(59 \%)$ \\
\hline High risk & $0(0 \%)$ & $16(15 \%)$ & $16(10 \%)$ \\
\hline \multicolumn{4}{|c|}{ Applied dose } \\
\hline $20 x 3.0 \mathrm{~Gy}$ & $48(100 \%)$ & $0(0 \%)$ & $48(30 \%)$ \\
\hline $21 \times 3.0 \mathrm{~Gy}$ & $0(0 \%)$ & $71(65 \%)$ & $71(45 \%)$ \\
\hline $22 \times 3.0 \mathrm{~Gy}$ & $0(0 \%)$ & $39(35 \%)$ & $39(225 \%)$ \\
\hline
\end{tabular}


the volume of contrast agent in CT image was substituted with water-density equivalent. CTV-PTV was $10 \mathrm{~mm}$ in all directions except for $8 \mathrm{~mm}$ towards the rectum in compliance with internal IGRT protocol. Prescribed doses are summarized above.

Dose-volume constraints for organs at risk are summarized in Table 2. For all patients, volumetric modulated RapidArc technique was planned with Aria 8.6 (20112013) and Aria 8.11 (2014). The dose was delivered by Clinac iX (Varian).

To prevent early toxicity, treatment for low-risk cancer was performed four days per week (with Wednesday typically as the free day), and for intermediate/high-risk alternately three and four days per week (usually Wednesday in odd weeks and Tuesday and Thursday in even weeks as free days). During therapy, daily cone beam CT was performed for image guidance purposes. Cone beam CT and planning CT images were co-registered based on soft tissue. Position correction was made every day with no action threshold using self-acting Table movement. Before each fraction, patients were asked to defecate, if possible, and exactly half an hour before irradiation to urinate and then drink $0.5 \mathrm{~L}$ of water. Patients underwent a regular weekly clinical examination for assessment of early toxicity. The worst grade observed during radiotherapy was recorded as a definitive early toxicity grade. The follow up visits were performed on the 1st, 3rd and then every 6 th month after radiotherapy was terminated, or more frequently, according to physician decision. Toxicity was evaluated according to the RTOG/ EORTC scale ${ }^{15}$. Patients who needed any kind of drug support were classified as G2. Three patients who needed urethral catheterization, were identified as G4.

\section{Statistical analysis}

In this study, descriptive statistics (average, median, frequency) were used.

\section{RESULTS}

\section{Low-risk patients}

48 patients with low-risk cancer underwent therapy on the prostate alone. 20 (42\%) of these were treated with neoadjuvant hormonal therapy administered by a urologist. Two (4\%) patients had transurethral prostatectomy in their medical history. Early genitourinary (GU) toxicity
Table 2. Dose-volume constraints.

\begin{tabular}{lc}
\hline & Maximal dose \\
& {$[\mathrm{Gy}]$ (in volume of organ) } \\
\hline Rectum & $63(15 \%)$ \\
& $58(20 \%)$ \\
& $54(25 \%)$ \\
& $50(35 \%)$ \\
& $42(50 \%)$ \\
Bladder & $68(15 \%)$ \\
& $63(25 \%)$ \\
& $59(35 \%)$ \\
Femoral heads & $55(50 \%)$ \\
\hline
\end{tabular}

was observed for grades $0,1,2,3$ and 4 in 20 (42\%), 18 (38\%), 9 (19\%), 0 and 1 (1\%), respectively; early gastrointestinal (GI) toxicity was recorded for grades 0,1 and 2 in $31(65 \%), 16(33 \%)$ and $1(2 \%)$ patients respectively.

\section{Intermediate and high-risk patiens}

94 patients with intermediate and 16 with high-risk cancer underwent therapy on prostate alone as one and prostate and $2 / 3$ of seminal vesicles as the second target volume. $65(59 \%)$ of thesewere treated with neoadjuvant and concomitant hormonal therapy. Two (2\%) patients had transurethral prostatectomy in their medical history. Early genitourinary (GU) toxicity was observed for grades $0,1,2,3$ and 4 in $53(48 \%), 42$ (38\%), 13 (12\%), 0 and 2 (2\%), respectively; Early gastrointestinal (GI) toxicity was recorded for grades 0,1 , and 2 in 88 (80\%), 21 (19\%), 1 ( $1 \%)$ and 0 patients, respectively.

\section{Cumulative results of all patients}

Altogether, 158 patients with localized prostate cancer were treated with hypofractionated schedule. 85 (54\%) were administred with neoadjuvant and 65 (41\%) with concomitant hormonal treatment as well. Early genitourinary (GU) toxicity was observed for grades $0,1,2,3$ and 4 in $73(46 \%), 60(38 \%), 22(14 \%), 0$ and $3(2 \%)$, respectively; early gastrointestinal (GI) toxicity was recorded for grades $0,1,2$ and 3 in 119 (75\%), 37 (23\%), and 2 (1\%) patients, respectively.

The results are summarized in Table 3.

Table 3. Early toxicity.

\begin{tabular}{|c|c|c|c|c|c|c|}
\hline & \multicolumn{2}{|c|}{ Low risk } & \multicolumn{2}{|c|}{ Intermediate + high risk } & \multicolumn{2}{|c|}{ All } \\
\hline & GI & GU & GI & GU & GI & GU \\
\hline G0 & $31(65 \%)$ & $20(42 \%)$ & $88(80 \%)$ & $53(48 \%)$ & $119(75 \%)$ & $73(46 \%)$ \\
\hline G1 & $16(33 \%)$ & $18(38 \%)$ & $21(19 \%)$ & $42(38 \%)$ & $37(23 \%)$ & $60(38 \%)$ \\
\hline $\mathrm{G} 2$ & $1(2 \%)$ & $9(19 \%)$ & $1(1 \%)$ & $13(12 \%)$ & $2(1 \%)$ & $22(14 \%)$ \\
\hline G3 & $0(0 \%)$ & $0(0 \%)$ & $0(0 \%)$ & $0(0 \%)$ & $0(0 \%)$ & $0(0 \%)$ \\
\hline G4 & $0(0 \%)$ & $1(1 \%)$ & $0(0 \%)$ & $2(2 \%)$ & $0(0 \%)$ & $3(2 \%)$ \\
\hline
\end{tabular}




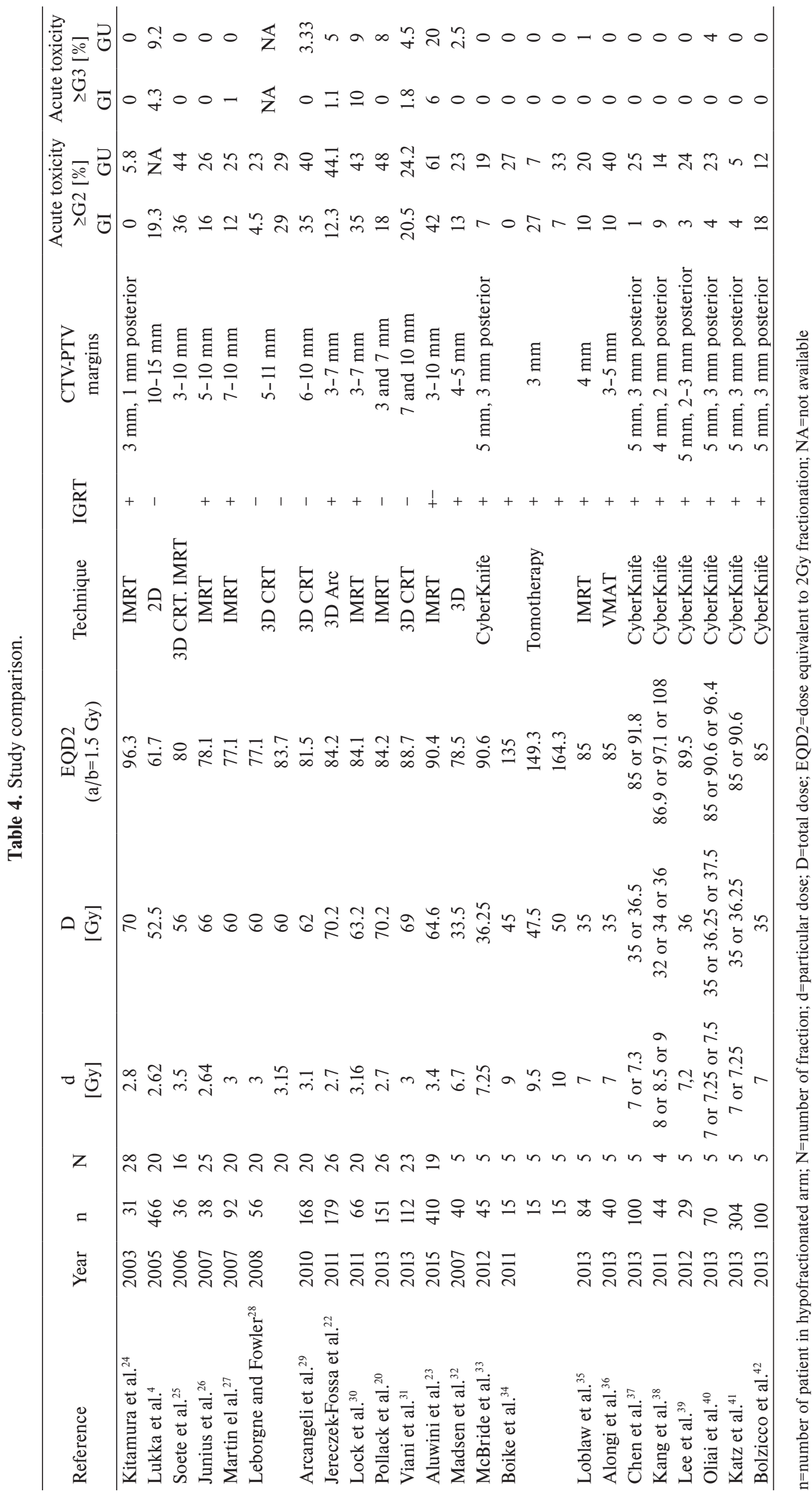




\section{DISCUSSION}

Technological progress in accuracy of radiation delivery dose enables reduction in irradiated volumes. This improvement enables application of different accelerated regimens and schedules, from mild hypofractionation to stereotactic techniques. Higher precision of dose delivery and image guidance is one approach for accelerated fractionation schedules. In prostate cancer, we there ia another assumption which is supported by different radiobiological characteristics. The concept that prostate cancer's $\alpha / \beta$ ratio is lower than $\alpha / \beta$ of rectum and bladder, was published by Brenner and Hall ${ }^{16}$. A number of other studies suggested high sensitivity dose per fraction. These would favor hypofractionated schedules ${ }^{17-19}$. Dasu and Toma-Dasu ${ }^{3}$ analyzed the clinical data of 14168 patients and concluded, that the $\alpha / \beta$ ratio is very low (1-1.7 Gy). In tumors with high $\alpha / \beta$ value, the late toxicity NTCP increases with increasing dose per fraction, while the TCP increases much more slowly. Reverse ratio is applicable in prostate cancer radiotherapy. With increasing prescribed daily dose, the TCP curve should increase faster than NTCP. Taking into account healthy tissues repopulation, we assume that early toxicity can be reduced by using less than five fractions per week. Owing to larger irradiated volume (seminal vesicles) and higher total dose in intermediate and high-risk patients, one and two free days a week alternately were needed to reach the isotoxic scheme in our radiobiological modeling, while only one free day was needed when prostate alone was irradiated.

The concept of hypofractionation has been tested in a few randomized and nonrandomized trials. The authors concerned have described early as well as chronic toxicity, as low or acceptable.

Arcangeli et al. ${ }^{6}$ tested a regimen with $20 \times 3.1 \mathrm{~Gy}$, 4 fractions per week versus $40 \times 2.0 \mathrm{~Gy}$ in patients with high-risk prostate cancer. Whole pelvis was not irradiated. No significant difference in toxicity was observed. With a median follow-up of 70 months, isoefficiency of both fractionation schedules was confirmed.

Pollack et al..$^{20}$ actualized the data of their randomized study which compared regimens $38 \times 2.0$ Gy versus $26 \times 2.7$ Gy. No significant difference was found in toxicity or in biochemical control.

Faria et. al. ${ }^{21}$ assessed 82 patients with intermediate risk prostate cancer without any hormonal therapy with a median follow up of 81 months. The applied dose was 22x3.0 Gy, 3D CRT technique, $7 \mathrm{~mm}$ CTV-PTV margin. G2 toxicity for GI was $18 \%$ and for GU $21 \%$ (worst recorded grade). In the last clinical evaluation, the level of G2 toxicity decreased to $2 \%$ and $7 \%$, respectively.

Jereczek-Fossa et al. ${ }^{22}$ assessed a group of 179 older men (median age 74 years) treated with dose $26 \times 2.7$ Gy with IGRT and smaller CTV-PTV margin versus 174 younger (median age 71 years) treated with a dose of 42x2.0 Gy without IGRT and bigger CTV-PTV margin. GI toxicity grade 2 or higher was recorded in $12.3 \%$ patients treated with hypofractionation and $6.3 \%$ patients treated with conventional fractionation $(P=0.014), \mathrm{GU}$ toxicity was $39.2 \%$ and $20.7 \%$ respectively $(P<0.0001)$.

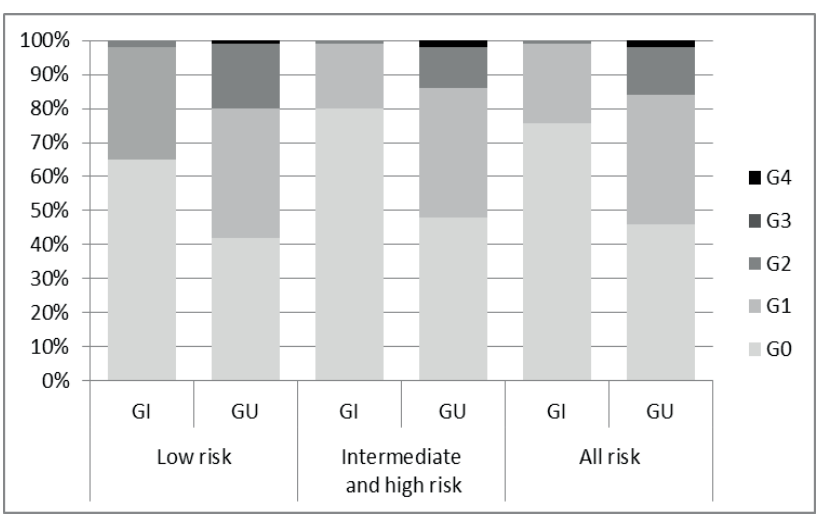

Fig. 1. Early toxicity distribution.

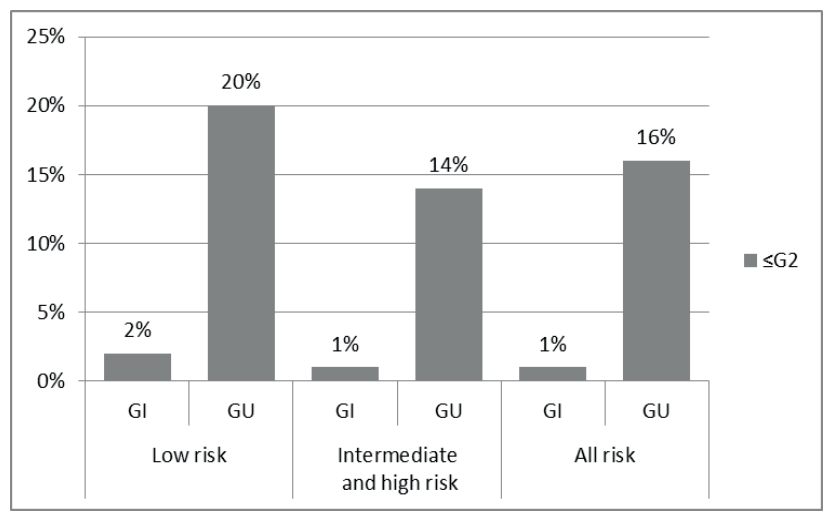

Fig. 2. Incidence of early toxicity $\geq \mathrm{G} 2$.

Aluwini et al. ${ }^{23}$ recently published results of phase III randomized study, enrolling patients with intermediate or high risk prostate cancer. 391 patients received 39x2.0 Gy, five fractions per week and 403 patients received 19x3.4 Gy, three fractions per week. IMRT with IGRT focusing on applied fiducial markers was used. Early GU toxicity worse than $\mathrm{G} 2$ was $58 \%$ versus $61 \%(P=0.43)$ and GI toxicity $31 \%$ versus $42 \%(P=0.0015)$ for conventional fractionation versus hypofractionation respectively.

Trials using extreme hypofractionated schedules show overall low early toxity. Most of them use robotic linear accelerator, image guidance with fuducials tracking and very small CTV-PTV margines or special imobilisation techniques.

These and other studies are summarized in Table 4.

These studies are difficult to compare owing to different dose delivery techniques, dose per fraction, usage of IGRT, etc. It can be said that most studies show mild early GI (4.5-42\%) and GU (7.6-61\%) toxicity $\geq \mathrm{G} 2$.

In comparison to the studies mentioned above, our study achieved low levels of early toxicity. This can be explained by choice of free days inserted into the schedule in combination with precise dose delivery represented by volumetric arc technique with daily cone beam image guidance.

Smaller CTV-PTV margines used contemporary in our clinic can show further lowering of early toxicity.

From a radiotherapy clinic time management point of view, the concept of free days can be better optimized. 
One example is a schedule with alternating two and three radiation days per week and dose per fraction which will preserve corresponding equivalent dose, as well as shorten all treatment periods in comparison with conventional fractionation.

\section{CONCLUSION}

This study confirms the feasibility of hypofractionated approach in themanagement of prostate cancer curative radiotherapy from the viewpoint of early toxicity. The dose 20-22x3.0 Gy, three to four days per week, is associated with acceptable early toxicity. Late toxicity and PSA response is not reported due to short follow-up.

Use of radiobiological principles in combination with precise dose delivery and image guidance systems is promising in terms of to very short radiotherapy course to the advantage of patients, hospitals and the public health system.

\section{ABBREVIATIONS}

3D-CRT, 3D Conformal Radiotherapy; d, Dose per fraction; D, Total dose; DVH, Dose volume histogram; EQD2, Dose equivalent to 2Gy fractionation; GI, Gastrointestinal; GS, Gleason Score; GU, Genitourinary; HART, Hypofractionated Accelerated Radiotherapy; IGRT, Image Guided Radiotherapy; IMRT, Intensity Modulated Radiotherapy; NCCN, National Comphrehensive Cancer Network.

Acknowledgement: This article is dedicated to the grant LO 1413.

Author contributions: All authors contributed equally to preparing the manuscript.

Conflict of interest statement: The authors state that there are no conflicts of interest regarding the publication of this article.

\section{REFERENCES}

1. Hanus M, Matouskova M, Dusek L. Prostate carcinoma. Current dilemma of urooncology. How to help the needed and not to harm the others. Klin Onkol 2013;26(3):170-8.

2. Strigari L, Arcangeli G, Arcangeli S, Benassi M. Mathematical model for evaluating incidence of acute rectal toxicity during conventional or hypofractionated radiotherapy courses for prostate cancer. Int J Radiat Oncol Biol Phys 2009;73(5):1454-60.

3. Dasu A, Toma-Dasu I. Prostate alpha/beta revisited -- an analysis of clinical results from 14168 patients. Acta Oncol 2012;51(8):963-74.

4. Lukka H, Hayter C, Julian JA, Warde P, Morris WJ, Gospodarowicz M, Levine M, Sathya J, Choo R, Prichard H, Brundage M, Kwan W. Randomized trial comparing two fractionation schedules for patients with localized prostate cancer. J Clin Oncol 2005;23(25):61328.

5. Yeoh EE, Botten RJ, Butters J, Di Matteo AC, Holloway RH, Fowler J. Hypofractionated versus conventionally fractionated radiotherapy for prostate carcinoma: final results of phase III randomized trial. Int J Radiat Oncol Biol Phys 2011;81(5):1271-8.
6. Arcangeli S, Strigari L, Gomellini S, Saracino B, Petrongari MG, Pinnaro P, Pinzi V, Arcangeli G. Updated results and patterns of failure in a randomized hypofractionation trial for high-risk prostate cancer. Int J Radiat Oncol Biol Phys 2012;84(5):1172-8.

7. Kuban DA, Nogueras-Gonzalez GM, Hamblin L, Lee AK, Choi S, Frank SJ, Nguyen QN, Hoffman KE, McGuire SE, Munsell MF. Preliminary Report of a Randomized Dose Escalation Trial for Prostate Cancer using Hypofractionation. Int J Radiat Oncol Biol Phys 78(3):S58-S9.

8. Otto K. Volumetric modulated arc therapy: IMRT in a single gantry arc. Med Phys 2008;35(1):310-7.

9. Mohler J, Bahnson RR, Boston B, Busby JE, D'Amico A, Eastham JA, Enke CA, George D, Horwitz EM, Huben RP, Kantoff P, Kawachi M, Kuettel M, Lange PH, Macvicar G, Plimack ER, Pow-Sang JM, Roach M, 3rd, Rohren E, Roth BJ, Shrieve DC, Smith MR, Srinivas S, Twardowski $\mathrm{P}$, Walsh PC. NCCN clinical practice guidelines in oncology: prostate cancer. J Natl Compr Canc Netw 2010;8(2):162-200.

10. D'Amico AV, Whittington R, Malkowicz SB, Schultz D, Blank K Broderick GA, Tomaszewski JE, Renshaw AA, Kaplan I, Beard CJ, Wein A. Biochemical outcome after radical prostatectomy, external beam radiation therapy, or interstitial radiation therapy for clinically localized prostate cancer. JAMA 1998;280(11):969-74.

11. Li XA, Wang JZ, Stewart RD, Dibiase SJ, Wang D, Lawton CA. Designing equivalent treatment regimens for prostate radiotherapy based on equivalent uniform dose. Br J Radiol 2008;81(961):59-68.

12. Michalski JM, Gay H, Jackson A, Tucker SL, Deasy JO. Radiation dosevolume effects in radiation-induced rectal injury. Int J Radiat Oncol Biol Phys 2010;76(3 Suppl):S123-9.

13. Viswanathan AN, Yorke ED, Marks LB, Eifel PJ, Shipley WU. Radiation dose-volume effects of the urinary bladder. Int J Radiat Oncol Biol Phys 2010;76(3 Suppl):S116-22.

14. Matula P, Koncik J, Dubinsky P, Jasencak M. BIOGRAY - A TOOL FOR SIMULTANEOUS MODELLING TCP/NTCP; EVALUATION OF DVH AND QUANTEC DATA. Radiother Oncol 2001; 98(Supplement 2):S26.

15. Cox JD, Stetz J, Pajak TF. Toxicity criteria of the Radiation Therapy Oncology Group (RTOG) and the European Organization for Research and Treatment of Cancer (EORTC). Int J Radiat Oncol Biol Phys 1995;31(5):1341-6.

16. Brenner DJ, Hall EJ. Fractionation and protraction for radiotherapy of prostate carcinoma. Int J Radiat Oncol Biol Phys 1999;43(5):1095101.

17. Ritter M, Forman J, Kupelian P, Lawton C, Petereit D. Hypofractionation for prostate cancer. Cancer J 2009;15(1):1-6.

18. Kupelian PA, Willoughby TR, Reddy CA, Klein EA, Mahadevan A. Hypofractionated Intensity-Modulated Radiotherapy (70 Gy at 2.5 Gy Per Fraction) for Localized Prostate Cancer: Cleveland Clinic Experience. Int J Radiat Oncol Biol Phys 68(5):1424-30.

19. Timmerman RD. An overview of hypofractionation and introduction to this issue of seminars in radiation oncology. Semin Radiat Oncol 2008;18(4):215-22.

20. Pollack A, Walker G, Horwitz EM, Price R, Feigenberg S, Konski AA, Stoyanova R, Movsas B, Greenberg RE, Uzzo RG, Ma C, Buyyounouski MK. Randomized trial of hypofractionated external-beam radiotherapy for prostate cancer. J Clin Oncol 2013;31(31):3860-8.

21. Faria S, Dal Pra A, Cury F, David M, Duclos M, Freeman CR, Souhami L. Treating intermediate-risk prostate cancer with hypofractionated external beam radiotherapy alone. Radiother Oncol 2011;101(3):486-9.

22. Jereczek-Fossa BA, Zerini D, Fodor C, Santoro L, Cambria R, Garibaldi C, Tagaste B, Vavassori A, Cattani F, Alterio D, Gherardi F, Serafini F Rocco B, Musi G, De Cobelli O, Orecchia R. Acute toxicity of imageguided hypofractionated radiotherapy for prostate cancer: nonrandomized comparison with conventional fractionation. Urol Oncol 2011;29(5):523-32.

23. Aluwini S, Pos F, Schimmel E, van Lin E, Krol S, van der Toorn PP, de Jager H, Dirkx M, Alemayehu WG, Heijmen B, Incrocci L. Hypofractionated versus conventionally fractionated radiotherapy for patients with prostate cancer (HYPRO): acute toxicity results from a randomised non-inferiority phase 3 trial. Lancet Oncol 2015;16(3):274-83.

24. Kitamura K, Shirato $H$, Shinohara N, Harabayashi T, Onimaru R, Fujita K, Shimizu S, Nonomura K, Koyanagi T, Miyasaka K. Reduction in acute morbidity using hypofractionated intensity-modulated radiation therapy assisted with a fluoroscopic real-time tumor-tracking system for prostate cancer: preliminary results of a phase I/II study. Cancer J 2003;9(4):268-76. 
25. Soete G, Arcangeli S, De Meerleer G, Landoni V, Fonteyne V, Arcangel G, De Neve W, Storme G. Phase II study of a four-week hypofractionated external beam radiotherapy regimen for prostate cancer: report on acute toxicity. Radiother Oncol 2006;80(1):78-81.

26. Junius S, Haustermans K, Bussels B, Oyen R, Vanstraelen B, Depuydt T, Verstraete J, Joniau S, Van Poppel H. Hypofractionated intensity modulated irradiation for localized prostate cancer, results from a phase I/II feasibility study. Radiat Oncol 2007;2:29.

27. Martin JM, Rosewall T, Bayley A, Bristow R, Chung P, Crook J, Gospodarowicz M, McLean M, Menard C, Milosevic M, Warde P, Catton C. Phase II trial of hypofractionated image-guided intensitymodulated radiotherapy for localized prostate adenocarcinoma. Int J Radiat Oncol Biol Phys 2007;69(4):1084-9.

28. Leborgne F, Fowler J. Acute toxicity after hypofractionated conformal radiotherapy for localized prostate cancer: nonrandomized contemporary comparison with standard fractionation. Int J Radiat Oncol Biol Phys 2008;72(3):770-6.

29. Arcangeli G, Saracino B, Gomellini S, Petrongari MG, Arcangeli S, Sentinelli S, Marzi S, Landoni V, Fowler J, Strigari L. A prospective phase III randomized trial of hypofractionation versus conventional fractionation in patients with high-risk prostate cancer. Int J Radiat Oncol Biol Phys 2010;78(1):11-8.

30. Lock M, Best L, Wong E, Bauman G, D'Souza D, Venkatesan V, Sexton T, Ahmad B, Izawa J, Rodrigues G. A Phase II trial of arc-based hypofractionated intensity-modulated radiotherapy in localized prostate cancer. Int J Radiat Oncol Biol Phys 2011;80(5):1306-15.

31. Viani GA, da Silva LB, da Silva BB, Crempe YB, Martins VS, Ferrari RJ, Polo MC, Rossi BT, Suguikawa E, Zulliani GC, Stefano EJ. Acute toxicity profile in prostate cancer with conventional and hypofractionated treatment. Radiat Oncol 2013;8:94.

32. Madsen BL, Hsi RA, Pham HT, Fowler JF, Esagui L, Corman J. Stereotactic hypofractionated accurate radiotherapy of the prostate (SHARP), 33.5 Gy in five fractions for localized disease: first clinical trial results. Int J Radiat Oncol Biol Phys 2007;67(4):1099-105.

33. McBride SM, Wong DS, Dombrowski JJ, Harkins B, Tapella P, Hanscom HN, Collins SP, Kaplan ID. Hypofractionated stereotactic body radiotherapy in low-risk prostate adenocarcinoma: preliminary results of a multi-institutional phase 1 feasibility trial. Cancer 2012;118(15):368190.
34. Boike TP, Lotan Y, Cho LC, Brindle J, DeRose P, Xie XJ, Yan J, Foster R, Pistenmaa D, Perkins A, Cooley S, Timmerman R. Phase I doseescalation study of stereotactic body radiation therapy for low- and intermediate-risk prostate cancer. J Clin Oncol 2011;29(15):2020-6.

35. Loblaw A, Cheung P, D'Alimonte L, Deabreu A, Mamedov A, Zhang L, Tang C, Quon H, Jain S, Pang G, Nam R. Prostate stereotactic ablative body radiotherapy using a standard linear accelerator: toxicity, biochemical, and pathological outcomes. Radiother Oncol 2013;107(2):153-8.

36. Alongi F, Cozzi L, Arcangeli S, Iftode C, Comito T, Villa E, Lobefalo F, Navarria P, Reggiori G, Mancosu P, Clerici E, Fogliata A, Tomatis S, Taverna G, Graziotti P, Scorsetti M. Linac based SBRT for prostate cancer in 5 fractions with VMAT and flattening filter free beams: preliminary report of a phase II study. Radiat Oncol 2013;8:171.

37. Chen LN, Suy S, Uhm S, Oermann EK, Ju AW, Chen V, Hanscom HN, Laing S, Kim JS, Lei S, Batipps GP, Kowalczyk K, Bandi G, Pahira J, McGeagh KG, Collins BT, Krishnan P, Dawson NA, Taylor KL, Dritschilo A, Lynch JH, Collins SP. Stereotactic body radiation therapy (SBRT) for clinically localized prostate cancer: the Georgetown University experience. Radiat Oncol 2013;8:58.

38. Kang JK, Cho CK, Choi CW, Yoo S, Kim MS, Yang K, Yoo H, Kim JH, Seo YS, Lee DH, Jo M. Image-guided stereotactic body radiation therapy for localized prostate cancer. Tumori 2011;97(1):43-8.

39. Lee YH, Son SH, Yoon SC, Yu M, Choi BO, Kim YS, Jang HS, Lee SN, Jang JS, Hwang TK. Stereotactic body radiotherapy for prostate cancer: a preliminary report. Asia Pac J Clin Oncol 2014;10(2):e46-53.

40. Oliai C, Lanciano R, Sprandio B, Yang J, Lamond J, Arrigo S, Good M, Mooreville M, Garber B, Brady LW. Stereotactic body radiation therapy for the primary treatment of localized prostate cancer. J Radiat Oncol 2013;2(1):63-70.

41. Katz AJ, Santoro M, Diblasio F, Ashley R. Stereotactic body radiotherapy for localized prostate cancer: disease control and quality of life at 6 years. Radiat Oncol 2013;8:118.

42. Bolzicco G, Favretto MS, Satariano N, Scremin E, Tambone C, Tasca A. A single-center study of 100 consecutive patients with localized prostate cancer treated with stereotactic body radiotherapy. BMC Urol 2013;13:49. 